\section{SUMMARY}

The UK's relative productivity performance has been revised (compared with the previous set of published results, following the update to the benchmarking exercise of prices across all Organisation for Economic Co-operation and Development countries in November 2007.

Revisions in the international comparisons of productivity (ICP) estimates released in February 2008 predominantly reflect these new estimates of purchasing power parities (PPPs). This article provides an overview of the methodology used by the Office for National Statistics in constructing estimates of ICP and gives more detail to help users understand why the PPP data were revised and the impact this had on the latest published set of ICP estimates.

\title{
International comparisons of productivity: an update to understanding revisions
}

T

he Office for National Statistics (ONS) has been publishing estimates of international comparisons of productivity (ICP) since October 2001. These show the UK's relative productivity performance, as measured by gross domestic product (GDP) per worker and per hour worked, against all other G7 countries (Canada, France, Germany, Italy, Japan and the United States). Using the current purchasing power parity (PPP) approach, this allows cross-sectional comparisons of productivity to be made.

These current PPP-based ICP estimates should only be used to compare the relative productivity of the UK at a particular point in time; comparisons of growth should be avoided. In October 2007, ONS published its first estimates of ICP based on the constant PPP approach that allows users to make international comparisons of productivity growth (see Dey-Chowdhury (2007) for details).

The ICP First Release is a biannual release reflecting the publication cycles of the component data, which are published by the Organisation for Economic Co-operation and Development (OECD). In September, the series is extended by a further year reflecting the first time data are available for the four component data series (as well as incorporating revisions to these data for past years). The subsequent February release is an update of these initial estimates, which incorporate revised GDP and PPP data.
In every release, a table of revisions is published that shows how the estimates have changed relative to the previous publication (in terms of percentage points). When there is a methodology-based change in estimating one of the four component data series for a particular country, there is potential for these revisions to be significant. This makes the revisions country-specific and can affect all the estimates back to 1990. For example, French hours worked data were heavily revised in the October 2006 release, reflecting an improved methodology to estimating overtime hours and hours worked in second jobs, which caused downward revisions to French ICP estimates for 1990 to 2004. If such a change affects the UK, then this will be reflected in revisions for all other G7 countries. Because ICP estimates based on the current PPP approach are indexed such that the UK is always equal to 100 , then revisions will feed into the relative productivity of the other countries. This was seen in October 2007, when the UK National Accounts incorporated improved estimates of own-account software investment that caused large upward revisions to UK GDP.

The revisions published in February 2008, however, were relatively large and broadbased. While the ranking of countries (in other words, the relative productivity comparisons) on both productivity measures has largely been unaffected, there are still quite large absolute changes in these 
estimates. This affects how the productivity gap of the UK with the other G7 countries is interpreted. Of most significance is the gap with the US which, for 2006, on the GDP per worker measure is now 28 per cent, an upward revision of five percentage points from the previously published estimate in October 2007.

The revisions that are presented in this article can be shown to be predominantly driven by revisions to the PPP data, reflecting the publication of 2005 benchmarked PPPs in November 2007. There is also the effect of revisions to the US implied GDP deflator, as well as Eurostat revising their PPPs back to 1995. This article is an update to Lau and Wallis (2005), which outlined details of the previous benchmarking exercise in 2002 and explains why these latest PPP data have been revised.

\section{Sources of revisions}

The ICP estimates that are produced by ONS are based on underlying data obtained from the OECD, which improves the comparability of these data. Each of the component series is country and year specific.

$$
\text { GDP per worker }_{i}=\frac{\text { GDP }_{i} / \text { PPP }_{i}}{\text { Employment }_{i}}
$$

GDP per hour worked $_{\mathrm{i}}=\frac{1 / \mathrm{PPP}_{\mathrm{i}}}{\text { Employment }_{\mathrm{i}} \times \text { Hours }_{\mathrm{i}}}$

These data are obtained from the following sources:

- GDP from the OECD Main Economic Indicators, published monthly

- PPP from the OECD PPP website at www.oecd.org/std/ppp, which is updated on a continual basis

- employment from the OECD Annual Labour Force Statistics, available annually, usually from August

- hours from the OECD Employment Outlook, published annually in July

The timing of the publication dates of these four component series explains why ONS publishes estimates of ICP in September and February. Country-specific revisions to any of these underlying sources will automatically feed into the ICP estimates published for that country.

There are two types of revisions: information-based and methodology-based. Information-based revisions refer to those that result as more data become available to estimate that particular component series. These are a feature of any data series as there is a trade-off between timeliness and accuracy of publishing data. In terms of ICP, information-based revisions predominantly affect the estimates published in the September release, but revised GDP and/or PPP data, if there are any, will also cause estimates published in February to be revised.

However, methodology-based revisions have the potential to cause significant revisions to ICP dating back to 1990 . These can occur for a number of reasons, principally efforts made by National Statistics Institutes (NSIs) to make these data more consistent with international guidelines such as the 1993 System of National Accounts (SNA 93). It should be noted that, although these initially cause one-off revisions that can be large in magnitude, they do improve the comparability of the data. This means that the estimates of ICP give a better indication of relative productivity as opposed to reflecting measurement type issues.

Whereas methodology-based revisions are less frequent, their impact on the published ICP estimates tend to be of a far more significant nature. Although such methodological changes do improve the comparability of these data, they can initially cause one-off sizeable revisions that require an explanation. Table $\mathbf{1}$ is an update from Lau and Wallis (2005), outlining all the methodological changes that have occurred since the publication of the September 2005 ICP estimates.

\section{Decomposition of latest set of revisions}

The ICP estimates published in February

2008 were largely revised due to the latest OECD-Eurostat PPP triennial

\section{Table 1}

\section{Sources of methodology-based revisions}

\begin{tabular}{ll}
\hline ICP release & Sources of revisions \\
\hline September 2005 & None \\
February 2006 & Back series of downward revisions to Japanese GDP data
\end{tabular}

October $2006 \quad$ Upward revisions to French hours worked data to take account of overtime hours and hours worked in second or higher jobs, causing downward revisions to the French ICP GDP per hour worked estimates

Upward revisions to Italian hours worked as a result of a change in source used by OECD

February 2007 Minor past revisions to Japan GDP and PPP data, the latter being revised because of changes in the implicit price deflators used to estimate PPPs for non-benchmarked years

October 2007 Incorporation of new improved methodology in estimating own-account software investment in the UK National Accounts. This led to upward revisions to UK GDP, causing downward revisions to ICP estimates for all other countries

February 2008 benchmarking programme, as well as revisions to the US implied GDP deflator and revisions carried out by Eurostat. The set of revisions is shown for both GDP per

orker and GDP per hour worked in Box 1. per worker for 2006 for all G7 countries (since ICP estimates are always indexed to 100 for the UK, revisions to the UK will always be zero). The revision refers to what was published for 2006 in February published in October 2007. For the purposes of this analysis, revisions have been presented to one decimal place.

It can be seen from Figure 1 that the estimates are being driven by revisions to the PPP data. In fact, these revisions would have been larger in absolute size had it not data in 2006, caused by the inclusion of a number of annual sources, in particular services inquiries and the international film and TV survey. Since all ICP estimates are indexed to 100 for the UK, an upward revisions to all other countries' estimates of GDP per worker (assuming there are no dditional source data revisions).

The latest benchmarked PPP data imply that the purchasing power of the pound has GDP per worker for the other G7 countries being revised upwards and so the relative productivity performance of the UK is feature of all the estimates dating back to 2002 (with the exception of France in 2004). The recently benchmarked PPP data been for an upward revision to UK GDP lower than previously published. This is also 


\section{Box 1}

\section{Revisions in the ICP February 2008 release}

Table 2 and Table $\mathbf{3}$ below show the latest revisions to ICP, measured by GDP per worker and GDP per hour worked, respectively. These are largely the result of revisions to PPPs caused by the 2005 PPP triennial benchmark results. There were largely no revisions to GDP data since the last publication of ICP in October 2007, the exception being for Japan in 2004 and 2005 and for the UK in 2006.

The latest set of benchmarked PPP data led to upward revisions to UK PPPs, implying that the relative purchasing power of the pound had fallen. PPPs are the rates of currency conversion that eliminate price level differences between countries. The upward revisions mean that essentially more pounds are needed to buy a representative basket of goods and services consumed in the US. This means that when UK GDP is converted into dollars using PPPs, that output is worth relatively less compared with the previous set of estimates. This explains the fall in relative UK productivity since 2002.

Table 2

\section{Revisions to GDP per worker - current PPPs}

\begin{tabular}{|c|c|c|c|c|c|c|c|c|c|}
\hline \multirow[b]{2}{*}{ Year } & \multirow[b]{2}{*}{ Canada } & \multirow[b]{2}{*}{ France } & \multirow[b]{2}{*}{ Germany } & \multirow[b]{2}{*}{ Italy } & \multirow[b]{2}{*}{ Japan } & \multirow[b]{2}{*}{ UK } & \multirow[b]{2}{*}{ USA } & \multicolumn{2}{|c|}{ G7 excluding } \\
\hline & & & & & & & & G7 & UK \\
\hline 1990 & 3 & -1 & $\mathrm{n} / \mathrm{a}$ & 1 & 3 & 0 & 3 & $\mathrm{n} / \mathrm{a}$ & $\mathrm{n} / \mathrm{a}$ \\
\hline 1991 & 3 & -2 & 5 & 1 & 3 & 0 & 3 & 3 & 3 \\
\hline 1992 & 3 & -2 & 6 & 1 & 3 & 0 & 3 & 3 & 3 \\
\hline 1993 & 3 & -1 & 5 & 1 & 3 & 0 & 3 & 3 & 3 \\
\hline 1994 & 3 & -1 & 5 & 1 & 3 & 0 & 3 & 3 & 3 \\
\hline 1995 & 3 & -1 & 5 & 1 & 3 & 0 & 3 & 3 & 3 \\
\hline 1996 & 2 & -2 & 4 & 0 & 2 & 0 & 3 & 2 & 2 \\
\hline 1997 & 2 & -3 & 4 & 1 & 2 & 0 & 2 & 2 & 2 \\
\hline 1998 & 2 & -3 & 4 & 1 & 2 & 0 & 3 & 2 & 2 \\
\hline 1999 & 1 & -2 & 5 & 0 & 1 & 0 & 2 & 1 & 2 \\
\hline 2000 & 1 & -2 & 2 & -1 & 1 & 0 & 1 & 1 & 1 \\
\hline 2001 & 1 & -2 & 3 & 2 & 1 & 0 & 1 & 1 & 1 \\
\hline 2002 & 3 & 3 & 5 & 0 & 2 & 0 & 3 & 3 & 3 \\
\hline 2003 & 4 & 2 & 1 & 2 & 2 & 0 & 3 & 2 & 2 \\
\hline 2004 & 3 & 0 & 2 & 1 & 1 & 0 & 3 & 2 & 2 \\
\hline 2005 & 7 & 2 & 4 & 3 & 3 & 0 & 6 & 4 & 5 \\
\hline 2006 & 6 & 1 & 4 & 3 & 4 & 0 & 5 & 4 & 4 \\
\hline
\end{tabular}

Note:

Revisions refer to the difference in index points between the data released on 19 February 2008 and the data released on 1 October 2007.

Source: Office for National Statistics

Table 3

Revisions to GDP per hour worked - current PPPs

\begin{tabular}{|c|c|c|c|c|c|c|c|c|c|}
\hline \multirow[b]{2}{*}{ Year } & \multirow[b]{2}{*}{ Canada } & \multirow[b]{2}{*}{ France } & \multirow[b]{2}{*}{ Germany } & \multirow[b]{2}{*}{ Italy } & \multirow[b]{2}{*}{ Japan } & \multirow[b]{2}{*}{ UK } & \multirow[b]{2}{*}{ USA } & \multicolumn{2}{|c|}{ G7 excluding } \\
\hline & & & & & & & & G7 & UK \\
\hline 1990 & 3 & -1 & $\mathrm{n} / \mathrm{a}$ & 1 & 3 & 0 & 3 & $\mathrm{n} / \mathrm{a}$ & $\mathrm{n} / \mathrm{a}$ \\
\hline 1991 & 3 & -2 & 6 & 1 & 3 & 0 & 3 & 3 & 3 \\
\hline 1992 & 3 & -2 & 6 & 1 & 3 & 0 & 3 & 3 & 3 \\
\hline 1993 & 3 & -1 & 6 & 1 & 3 & 0 & 3 & 3 & 3 \\
\hline 1994 & 3 & -1 & 6 & 1 & 2 & 0 & 3 & 3 & 3 \\
\hline 1995 & 3 & -1 & 6 & 1 & 3 & 0 & 3 & 3 & 3 \\
\hline 1996 & 2 & -2 & 5 & 0 & 2 & 0 & 2 & 2 & 2 \\
\hline 1997 & 2 & -3 & 4 & 1 & 2 & 0 & 2 & 2 & 2 \\
\hline 1998 & 2 & -3 & 4 & 1 & 2 & 0 & 2 & 2 & 2 \\
\hline 1999 & 1 & -3 & 5 & 0 & 1 & 0 & 2 & 1 & 1 \\
\hline 2000 & 1 & -3 & 2 & -1 & 1 & 0 & 1 & 0 & 1 \\
\hline 2001 & 1 & -2 & 3 & 2 & 1 & 0 & 1 & 1 & 1 \\
\hline 2002 & 3 & 3 & 5 & 0 & 2 & 0 & 3 & 3 & 3 \\
\hline 2003 & 4 & 2 & 2 & 2 & 1 & 0 & 3 & 2 & 2 \\
\hline 2004 & 3 & 0 & 2 & 1 & 1 & 0 & 2 & 2 & 2 \\
\hline 2005 & 7 & 2 & 4 & 3 & 3 & 0 & 6 & 4 & 5 \\
\hline 2006 & 6 & 1 & 5 & 3 & 4 & 0 & 5 & 4 & 4 \\
\hline
\end{tabular}

Note:

Revisions refer to the difference in index points between the data released on 19 February 2008 and the data released on 1 October 2007. 


\section{Figure 1

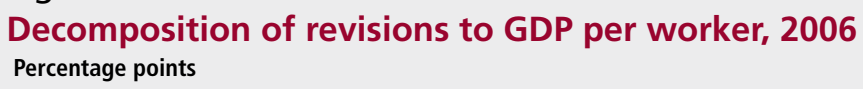

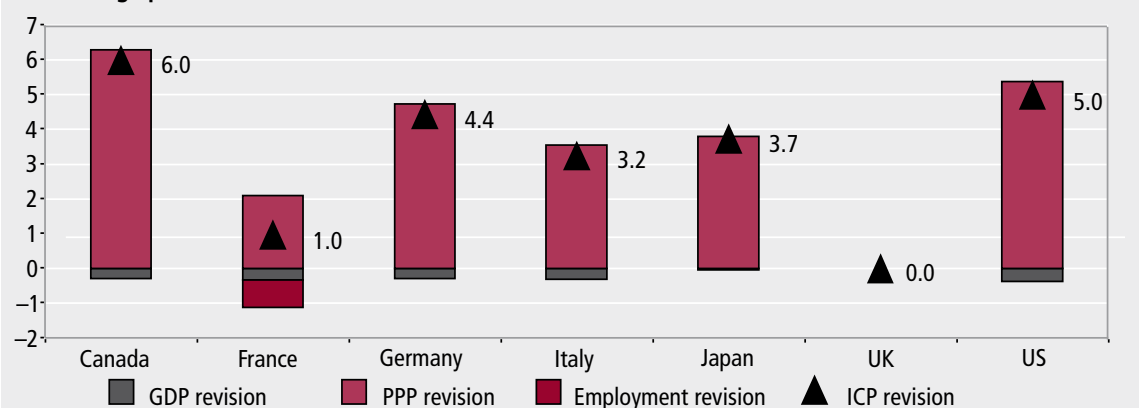

imply that the relative purchasing power of the pound has fallen, which explains these revisions (see Box 1).

As an aside, ICP revisions published in February usually only reflect revised GDP and/or PPP data. This is because both the employment and the hours worked series are only updated once a year, meaning that the same denominator series are used as in the previous autumn's release. However, the February 2008 release also incorporated revisions to French employment data. The reason for this was that these data were not available in time for the October 2007 release. ONS decided to extrapolate an employment estimate for 2006, applying the previous annual growth rate to the 2005 estimates. The actual data were available in time for the February 2008 release and were incorporated into this set of estimates. The latest French employment data also included revisions to data for 2002 to 2005 , inclusive. The upward revision to French employment data would have had the effect of lowering productivity estimates. However, this was more than offset by the effect of the French PPP revisions.

\section{PPP revisions}

There are essentially three main factors explaining revisions to PPPs:

- OECD-Eurostat triennial benchmarking

- revisions to the implicit GDP deflator for the US

- revisions made by Eurostat

\section{OECD-Eurostat triennial}

benchmarking

PPPs are jointly provided by the Eurostat and OECD. For 2005, this covered 45 countries, 31 being produced by Eurostat and the remaining 14 by OECD. Summarising the programme, Eurostat produces annual benchmarked estimates whereas OECD produces benchmarked data every three years. Estimates for intervening years for OECD-supervised countries are based on a method of extrapolation.

Eurostat implements a rolling benchmark approach, which can be summarised in three broad steps (see OECD PPP Methodological Manual, 2005 for details):

- for year $t$, prices for a group of similarly defined goods and services are collected. Price data for each country relating to the reference year $t$ are collected for each of these 'basic headings. This forms the basis of the relative prices that are used to construct PPPs

- for year $\mathrm{t}+1$, about a third of these are replaced by new PPPs calculated using prices collected during $\mathrm{t}+1$. The remainder of these data are extrapolated, meaning that all the basic headings now refer to year $t+1$

- these relative prices are then aggregated using expenditure weights for $t+1$; the basic headings provide the basis for these weights. This means that the PPPs refer to the reference year of $t+1$

This continual process of replacing prices for the basic headings, extrapolation and re-aggregation forms the three-year rolling benchmark process, enabling Eurostat to provide annual estimates of PPPs for the 31 countries that it currently coordinates. This covers the PPP estimates for France, Germany, Italy and the UK. Estimates for these countries are subject to a three-year rolling revisions policy. In the latest set of estimates published in November 2007, preliminary PPP estimates for 2006 were published, along with revised PPPs for 2005 and final PPPs for 2004. This threeyear rolling revisions policy, which reflects revised prices and expenditure data, are in line with SNA 93 deliveries. This explains the revisions to the PPPs published for
France, Germany, Italy and the UK. The source of the PPP revisions for these countries reflected revised input data.

OECD publishes estimates every three years, with estimates for the interim years being based on a method of extrapolation. The extrapolation is based on relative rates of inflation for each country, as measured by the implicit GDP deflator. The reason that estimates are produced every three years is because of some of the difficulties associated with the rolling benchmark when dealing with certain basic headings. For example, it is costly to extrapolate the prices of capital goods, so OECD decided that it would publish estimates every three years rather than on an annual basis. (Incidentally, Eurostat price capital goods every two years and estimate the PPPs for the interim year based on interpolation.) In terms of the G7 countries, these triennial estimates cover Canada, Japan and the US.

Prior to the latest set of benchmarked PPP data, estimates for 2003 to 2005 inclusive were based on extrapolation from the previous benchmark year, which was 2002. However, the recently benchmarked data for 2005 would have an impact in terms of these data. This is because the method of estimation for PPPs in these years would have changed. Instead, benchmarked estimates, actually based on price and expenditure data, replaced the previous extrapolated 2005 results. For 2003 and 2004, the data would have been revised, because they are now interpolated between 2002 and 2005 rather than extrapolated from 2002. The PPP estimates are then smoothed between these two benchmarks, which would have led to potentially significant revisions. There is greater scope for PPP revisions for these countries as they reflected the use of actual input data for 2005 as well as the effects these had on extrapolating estimates for 2003 and 2004.

OECD integrates the annual benchmark results provided by Eurostat for the European countries into their programme, meaning that benchmarked results for all 45 countries are available every three years. The latest of these were published in November 2007, with results being benchmarked for 2005. It should be noted that the 2006 estimates for countries supervised by OECD are still provisional and are subject to revisions in the short term. This is illustrated in Figure 2. 


\section{Figure 2}

\section{The OECD-Eurostat PPP programme}

\begin{tabular}{|c|c|c|c|c|c|c|c|c|c|c|c|c|c|c|c|c|c|}
\hline & 1990 & 1991 & 1992 & 1993 & 1994 & 1995 & 1996 & 1997 & 1998 & 1999 & 2000 & 2001 & 2002 & 2003 & 2004 & 2005 & 2006 \\
\hline $\begin{array}{l}\text { Non-EU } \\
\text { countries }\end{array}$ & \multicolumn{9}{|c|}{$\begin{array}{l}\text { Extrapolated using the relative rates of inflation between countries as measured by their } \\
\text { implicit price deflators for GDP }\end{array}$} & \multirow{2}{*}{ 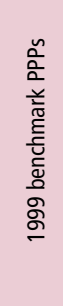 } & \multicolumn{2}{|c|}{ OECD estimates } & \multirow{2}{*}{ 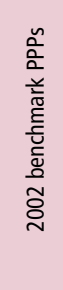 } & \multicolumn{2}{|c|}{ OECD estimates } & \multirow{2}{*}{ 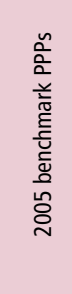 } & $\begin{array}{c}\text { Provis- } \\
\text { ional }\end{array}$ \\
\hline $\begin{array}{c}\text { EU } \\
\text { countries }\end{array}$ & \multicolumn{5}{|c|}{$\begin{array}{c}\text { "Extrapolated using the relative rates of inflation } \\
\text { between countries as measured by their implicit } \\
\text { price deflators for GDP }\end{array}$} & \multicolumn{4}{|c|}{$\begin{array}{l}\text { Annual benchmark results provided by } \\
\text { Eurostat }\end{array}$} & & \multicolumn{2}{|c|}{$\begin{array}{l}\text { Annual } \\
\text { benchmark results } \\
\text { provided by } \\
\text { Eurostat }\end{array}$} & & \multicolumn{2}{|c|}{$\begin{array}{l}\text { Annual } \\
\text { benchmark results } \\
\text { provided by } \\
\text { Eurostat }\end{array}$} & & $\begin{array}{c}\text { Provis- } \\
\text { ional }\end{array}$ \\
\hline
\end{tabular}

For non-EU countries, PPPs before 1999 are calculated using extrapolation. For EU countries, extrapolation is used to calculate PPPs before 1995. Extrapolation is described in more detail below. As changes in PPPs depend directly on relative rates of inflation in different countries, this method produces robust estimates provided they are not too remote from the base year and there have been no significant changes in price or expenditure structures within countries. For the extrapolation, the base year for non-EU countries is 1999 while for EU countries it is 1995 .

From 1995 onwards, PPPs for EU countries are annual benchmark results provided by Eurostat. In 2002, Eurostat undertook a thorough revision of its PPPs. The revisions concerned PPPs for the years 1995 to 2000 and corrected the inconsistencies arising from countries moving towards the European System of Accounts 1995 at different points in time. The results were published in November 2003.

For non-EU countries, the PPPs for 2000 and 2001 are the geometric averages of the interpolated results using the 1999 and 2002 benchmarks as the base years. Similarly, the PPPs for 2003 and 2004 use the 2002 and 2005 benchmarks as the base years.

PPPs for all countries are triennial benchmark results calculated jointly by the OECD and Eurostat.

For EU countries these are preliminary annual benchmark results provided by Eurostat. PPPs for non-EU countries are OECD estimates based on extrapolation. These estimates and preliminary results should be interpreted with caution as they are subject to revision.

Extrapolation: when estimating PPPs using extrapolation, the PPPs for the base year are carried forward (or backwards) by the relative rates of inflation in different countries as measured by implicit price deflators for GDP. Specifically, a country's PPP for year $t+n$ (or $t-n$ ) is obtained by multiplying its PPP for the base year $t$ by its implicit price deflator for GDP for year $t+n$ (or $t-n$ ) and then dividing by the implicit GDP deflator for year $t+n$ (or $t-n)$ for the reference country. The choice of reference country does not influence the final result and in practice the OECD uses the United States. Note also that PPPs that have been extrapolated backwards are sometimes referred to as backdated PPPs.

\section{Revisions to the implicit GDP deflator} for the US

There are additional sources of revisions to PPPs that go back to 1990 . The 14 countries for which OECD produces PPPs will be affected if there are country specific revisions to their implicit GDP deflator. This is because, as shown in Figure 2, PPPs for an OECD country are interpolated or extrapolated for non-benchmark years based on movements in that country's implicit GDP deflator. However, the implicit GDP deflator for the US has been revised, which has caused PPPs for all countries to be revised. This is because PPPs are constructed as a relative to the US. This explains why PPP revisions (and ICP revisions) date back to 1990 .

\section{Revisions made by Eurostat}

In addition, Eurostat have also revised the PPP series back to 1995 for the 31 countries that it coordinates. PPPs are subject to continual revisions, which partly reflect NSIs incorporating changes to their National Accounts in line with the SNA 93. This can result in the inclusion of new methodologies that provide better, more comparable estimates of economic activity in that country. For example, in 2007, improved estimates of own-account software were incorporated into the UK
National Accounts. The impact of this methodological change was to increase UK GDP and these were reflected in the October 2007 ICP release. However, these were not then reflected in the expenditure weights used to aggregate PPPs, but the latest set of revised PPPs has been updated to take this into account. Also, most countries have introduced estimates of Financial Intermediation Services Indirectly Measured (FISIM) into their National Accounts. Conceptually, FISIM can be thought of as having a level effect on the output measure of GDP, that is, the output of the banking services, but it will also have an impact on the expenditure side. This is because financial intermediaries provide these services to consumers, businesses, governments and the rest of world.

\section{Constant PPP approach}

In October 2007, ONS published their first estimates of ICP using the constant PPP approach (Dey-Chowdhury 2007). Estimates based on the current PPP approach give the best indication of international comparisons at a particular point in time. This is because the PPPs, which are country and year specific, give the best estimation of that country's price structure in that particular year. While these are suitable for cross-sectional analyses, it is not recommended that users infer productivity growth from these estimates. This is because the use of current PPPs means it is not possible to separately identify the price and volume effect in output growth. For productivity growth analyses, it is only changes in volume that matter.

The constant PPP approach, in line with OECD recommendations, fixes PPPs to a base year and uses growth in volume of each country's GDP to extrapolate both backwards and forwards. The advantage of this approach is that it enables the relative movements of volume growth to be captured, allowing comparisons of productivity growth.

Revisions to the constant PPP-based ICP estimates are almost non-existent, which is consistent with the source of revisions in the February 2008 release. In this approach, PPPs are fixed to a base year which, incidentally, has been updated to 2005 to reflect the latest benchmarked PPP data. Whereas the latest set of benchmarked results will affect the underlying productivity ratio, this will not be as directly observed once volume growth rates have been used to extrapolate from the base year and once all the data have been indexed to 100 for the reference year (1991). Significant revisions to these set of 
ICP estimates will only occur if there have been revisions to volume measures of GDP; revisions to PPPs have minimal effects. This is a characteristic of any methodology that makes use of a fixed-base approach; a chainlinked approach would have incorporated these PPP revisions.

\section{Conclusions}

This article has provided an overview of why revisions to ICP estimates occur in general, and explains why these revisions have been observed in the February 2008 release. These have been predominantly driven by the publication of 2005 benchmarked PPP data, in accordance with the OECD-Eurostat triennial benchmarking exercise programme, which has led to large revisions to the PPP data. These have also been caused by the recent revisions to the implicit GDP deflator for the US, which has caused a back series of PPP revisions for all countries. It has also been shown why revisions to PPPs do not visibly feed thorough to the constant PPP-based ICP estimates that are now published by ONS.

ICP will always be susceptible to oneoff revisions, reflecting changes that may occur to the component data series. In particular, PPPs are susceptible to continual revisions, reflecting both changes in price data and changes in National Accounts data. Depending on the nature of the change, these may cause country-specific changes or wider changes. Due to the continual cycle of source data revisions, users may wish to focus more on relative changes in productivity than just on absolute productivity levels, which are more susceptible to revisions. It should be stressed though that the long-run implication is that these revisions will improve the comparability of the data, enhancing the quality of productivity comparisons.

\section{ACKNOWLEDGEMENTS}

The author is grateful for the contributions made by David Baran (ONS) and Gavin Wallis (HM Treasury) in preparing this article.

\section{CONTACT}

(질ㅇons.gsi.gov.uk

\section{REFERENCES}

Dey-Chowdhury S (2006) 'Methodological Note: International comparison of economic activity', Economic Trends 633, pp 23-8 and at

www. statistics.gov.uk/cci/article. asp? $i d=1614$

Dey-Chowdhury S (2007) 'International comparisons of productivity: recommended used of the current and constant PPP approach' Economic \& Labour Market Review 1(8), pp 33-9 and at

www.statistics. gov.uk/cci/article. $a s p ? i d=1844$

Lau E and Wallis G (2005) 'International comparisons of productivity: a technical note on revisions and interpretation', Economic Trends 617, pp 42-56 and at www.statistics.gov.uk/cci/article. asp? $i d=1120$

Organisation for Economic Co-operation and Development (2005) PPP Methodological

Manual at

www.oecd.org/std/ppp/manual

Office for National Statistics International Comparisons of Productivity First Release, February 2008 at

www.statistics.gov.uk/statbase/

product.asp?vlnk=9671 